\title{
“Zooming" Across the Globe: Using Technology to Partner in Teaching
}

\author{
Maria Claver \\ California State University
}

\author{
Tsuann Kuo \\ Chung Shan Medical University \\ Casey Goeller \\ California State University
}

Population aging is a global phenomenon and teaching gerontology has moved from domestic to international. The purpose of this paper is to introduce a cross-continent, online "global aging" course designed by gerontological faculty in the United States and Taiwan. Most recently using Zoom, students engaged with global partners to learn about aging topics with an emphasis on the role of cultural and social contexts in the aging process. Results from evaluations by students, global partners and faculty showed that not only did the course expand their world views but they gained confidence in working with older adults in diverse cultures.

Keywords: global aging, online course, gerontology curriculum, teaching partnership, cultural diversity

\section{INTRODUCTION}

The rapid aging of the world's population is a global phenomenon. There is much to learn from the manner in which other countries are preparing to care for their older adults. Gerontology faculty in the United States and Taiwan, supported by global partners in Canada, India, Japan, Malaysia, Mexico, Netherlands, Norway, Singapore, and Spain have offered "Global Aging" at California State University, Long Beach (CSULB), a synchronous ("real time"), online course, most recently offered via Zoom (Zoom Video Communications, Inc., 2020). Six aging-related topics (e.g., Caregiving, Death \& Dying) were covered through lectures and assigned tasks for small groups to complete in collaboration with their global partners.

The purpose of this paper is to introduce the creation and implementation of an online global aging course from the perspective of the host faculty, global partners, and students. This course has been offered eight times since 2010. The authors ventured into designing a global course including gerontologists from different countries (rather than talking about people from different countries and cultures). The course evolved and was modified by incorporating the input of global aging educators at various aging conferences and presentations. Information on technological support and details about how classes were conducted will be shared to encourage others to consider the incorporation of global collaboration supported by technology in their educational pursuits. 


\section{The Importance of Global Aging Curriculum}

Global Aging has become an important topic of interest in academic settings, clinical practice and for trans-national families (Fitzgerald, 2015; Kunkel, Brown, \& Whittington, 2014; Shenk \& Groger, 2005; WHO and NIH, 2011). Elliott (2005) stressed that incorporating cross-cultural perspectives into teaching on aging can sensitize students in the United States to understand the varying experiences of aging around the globe. Different cultures cannot be understood outside of their context. Thus, studying global aging allows students to learn how different countries react in strikingly different ways to the same aging issue (Holmes \& Holmes, 1995).

To cultivate cultural diversity and care principles to impact future practitioners, Shenk and Groger (2005) suggested that content of global aging courses should include the following concepts: (1) culture as flexible, constantly changing, dynamic and complex; (2) the cultural and social context of any human being's life as having a tremendous influence on that human being's worldview; and (3) people come from specific cultural/ethnic backgrounds and have culturally shaped beliefs, practices, kinship relationships, moral attitude and worldviews. The authors suggest that to serve diverse elders effectively, one should enter into the cultural and social world of the particular elder. As for teaching methodologies or media, Nandan (2005) examined the influence of religions while Yahnke (2005) used international cinema and Waxman (2008) used literature to explore cross-cultural aging beliefs among the elderly. For study materials besides up-to-date internet searching, textbooks focused on international aging have been more available in recent years (Kunkel, Brown \& Whittington, 2014; Li, 2013, McDaniel \& Zimmer, 2013).

\section{Global Aging Course}

The collaboration started with the main course called "Global Aging," offered at the California State the University, Long Beach (CSULB) in the United States, and in conjunction with a comparable course called "Aging and Long Term Care," offered at both the Central Taiwan University of Science and Technology and Chung Shan Medical University in Taiwan. The Global Aging course has six learning objectives. The first is to give students a good idea of the fact that the United States is not the only country facing a tremendous population shift. Older adults (those aged 65 or older) are becoming a large proportion of the population in many countries. The second learning goal is to address ethical issues that arise when we are planning for and caring for an older population. The third learning objective is to discuss several trends that influence economic challenges in the US and other countries. The fourth learning objective is to compare aging experiences for elders in various countries. Specifically, we examine the following areas: politics/policy formation, health, family roles and relationships, caregiving, work and retirement, economic well-being, spirituality and housing. The fifth learning objective is to teach students how to critically evaluate research-based information that can help them understand global aging. This happens throughout the course through lectures and assignments. The last learning objective is to discuss the role of culture in forming attitudes toward aging and old age. Student contact with their global partners is essential in helping meet these learning objectives, as are the materials that students present for small group presentations.

\section{METHODS}

\section{The Role of Technology in Global Aging}

Global Aging was structured as a synchronous (real-time) online course. When the course was developed and first offered, the Elluminate audio and video conferencing program was supported by the university and used to teach the course. Challenges associated with the use of the Elluminate program centered around unreliable connection. In 2019, the host university adopted Zoom as the campussupported audio and video conferencing program. Zoom's features make it a highly effective tool for teaching a synchronous, online course: a chat box, participant list, breakout rooms, recording of sessions, ability to share the screen, a whiteboard, audio and video capabilities that can be muted by the participants or host, reliable connectability, the ability of students to call in using a telephone if they 
cannot access a computer, and the inclusion of guests (e.g., global partners) that are not enrolled students in the course. During the first session of the course, the instructor gave students an orientation to Zoom, allowing them to practice using the features and ensure that they could connect to the course.

\section{Global Aging Course Management}

Students were divided into small groups of four to five students and each small group was matched with a global partner. The class size ranged from 12 students in the first year it was offered to 30 students in 2019 , when it was most recently offered. We created separate Elluminate "virtual" rooms for each group to conduct their meetings with the global partners, although students were also welcomed to communicate with global partners via email.

The course was divided into six main topics (caregiving, death and dying, healthcare, economic security, spirituality, and retirement) and two weeks were dedicated to each topic. The first session of each topic was a lecture about the topic (using Powerpoint slides, film clips, and other media). At the end of the lecture, students received an assignment that their small group had to accomplish and present by the following class session a week later. The second session of each topic consisted of small group presentations addressing the assignment. Examples of small group assignments included: interviewing the group's global partner, presenting a film clip about the topic with a description, comparing a policy of a partner country with policy in the U.S., designing and administering a brief survey, and finding an empirical journal article about the week's topic and summarizing it for the class. To reinforce these synchronous meetings, a number of weekly student reflections were posted by each student individually and asynchronously to enhance learning opportunities.

\section{The Role of the Global Partner}

Whereas in 2010 global partners served as consultants to small groups of students who had to complete assignments every two weeks, the connection with global partners was further deepened when the course was offered in 2012. We decided to pose four tasks and have students in the U.S. and Taiwan collaboratively work to develop products related to those tasks. U.S. students were put into four groups of 4-5 students each and were matched with a colleague from Taiwan. Each team was assigned one of the following topics: a) Create a governmental policy about a family's responsibility in caregiving for older adults, b) What would your ideal nursing home look like?, c) Design a campaign to promote positive images of aging, and d) Create a plan to incorporate older adults and their wisdom/experience into solving problems faced by society. The assignment was broken down into four components: a) Outline the content of the project, b) Create a video, Prezi, or other presentation to address the topic prompt, c) Reflect upon issues that were easiest to agree upon/most challenging to agree upon. How did cultural beliefs play a role in this process and the outcome? At each phase, the American and Taiwanese students had to check in with each other and resolve disagreements as well as incorporate cultural values into the result. Each semester of Global Aging was a little different depending on opportunities to work with global partners and their students.

\section{Course Evaluations}

Feedback about the course was gathered using student course evaluations provided by the universities. The course evaluations include Likert-scale items regarding students' satisfaction with the course content, instructor characteristics (e.g., availability during office hours, effectiveness in teaching), and provides space for students to comment openly on the strengths and weaknesses of the course. The results are based on the open-ended comments provided by students in the United States and Taiwan. Global partner perspectives were gathered through debriefing exchanges between the course instructors and global partners. The faculty perspectives are those of the authors of this paper. 


\section{RESULTS}

As a result of continuous improvement and adjustment in the course, course evaluation results demonstrate significant impacts on students, global partners, and faculty. The perspectives from the faculty, students and global partners are discussed below.

\section{Global Partner Perspective}

The global partners for this course worked with a small group of students whose focus was aging issues in Taiwan. The participation with the students was through Elluminate/Zoom or emails. The global partners had the following roles: to provide knowledge and resources for each of the six topic areas, to provide answers to students' questions about the specific country, to comment on the films and projects that students would present in class, and to provide immediate responses to students' presentations and faculty lectures during the Elluminate/Zoom sessions. From the global partner perspective, students were proactive in gathering resources and information, which provided them with an opportunity for a global vision and more worldly views on aging. Since students had to find information on each of the six topics, they were likely to find information that would most applicable to real life. Lastly, hands-on projects requiring students to gather films or news from the internet formed a practical learning platform for global learning.

\section{Faculty Perspective}

From a faculty perspective, the greatest success of the Global Aging class was the ability to include global partners. We felt that this format allowed a significant amount of student-directed learning, rather than waiting to be "fed" information. The lectures provided background about the issue, but the in-depth inquiry was left to the students. We were able to record the Elluminate/Zoom sessions, so that students that missed class or missed material during a session could re-watch and listen to the session. Lastly, we feel that a positive result of group work is that the individual talents of each student are allowed to shine. Students tend to take on jobs within the group that they are most comfortable and confident with. For example, one student in the course is not a strong writer but was a very effective presenter.

Despite the overwhelming success of this course, there are challenges that must be considered. First, accessibility to the technology (e.g., computer, WiFi) required for full participation in the course may not be easily available for all students. Therefore, it is important that faculty teaching a synchronous online course explore alternative resources for students that need them, such as computers at the campus library. Second, there are challenges inherent in small group work. It is helpful to spend some class time reviewing tips for successful group collaboration. Lastly, although global partners were excited and willing to participate in class sessions, time zones did not always make that possible. To foster connection between global partners and students, we asked each global partner to record a brief video introduction and small groups of students did the same.

\section{Student Perspective}

From the student evaluations for this course, students felt that the information from this course was applicable to their careers. They reported enjoying learning and using Elluminate/Zoom. One student reported that he/she learned more than he/she expected. The online format was popular with the students. Another student stated, "I wish more universities offered this course." Students in Taiwan also wrote that they learned first-hand information from their American counterparts, which challenged many of their stereotypes about how older adults lived, how long-term care services were arranged and how life-long learning programs promoted active aging in the U.S.

In addition, in 2012, students from Taiwan participated in "hosting" students from the United States by exchanging what they learned in their respective aging courses. For example, on the topic of healthcare, students shared their "imaginations of what nursing homes should look like." Students from the United States and Taiwan shared their designs of nursing homes. Both groups of students not only learned about different cultures, regulations, and design concerns related to nursing homes, but also appreciated the 
introduction of new concepts including the use of technology for older adult care. As Taiwanese students shared in the course evaluation, the learning process involving exchanges from American students has: (1) "opened my eyes by seeing and talking to real people (the American fellow students) who can share their own perspectives when before only can be learned from the textbooks," (2) "made me realize that each country has its own problems, so we should not just envy or praise how good other countries are. We need good frameworks to examine each country with critical thinking," and (3) "reminded me how important culture, context, and government system are in designing policies or services for older adults in each country."

\section{DISCUSSION}

\section{Lessons Learned}

Several lessons have been learned from offering this course multiple times. Instructors should fully prepare global partners for their role in the course, including providing the partners with a syllabus and a copy of the assignments. As mentioned earlier, spend some time orienting students to the Zoom technology and techniques for successful small group work. Lectures via Zoom should last no longer than one hour and should include multiple opportunities for student interaction and discussion. Related to student interaction and depending on the size of the class, use the Zoom chat box rather than granting all students microphone/video privileges. If using small group presentations, limit them to 15 minutes and require presenters to include interactive activities. Lastly, require students to send the global partner an introductory video at the start of the course and a thank you note or video at the conclusion of the course.

\section{Future Endeavors in Global Aging}

This course has evolved from students learning information from textbooks, journal articles, websites, and questions exchanged by emails between different countries, to creating joint projects that allow students from different countries to work together to address similar issues about aging. While the use of information technology has helped advance the learning objectives, the authors are actively planning for the next step. With the population aging globally, many countries are starting to discuss designing a common course syllabus so students across the world can have basic knowledge and cover common topics about aging. A conceptual model of the globalization of gerontology education is proposed to require professional organizations, global partners, and U.S. scholars to work together to establish a standardized course syllabus for teaching global aging (Mwangi et al., 2012). The global comparisons assigned to students should also emphasize that culture and socio-structural factors play an important part in how policies and services are implemented (Hou, 2018). As the network of global partners expands, it is our hope to increase the number of countries being studied. Furthermore, with grants, fund-raising and university support, the goal will be to take global aging further by creating actual field trips or study exchanges to the other countries so students can witness what they learn in the real world. Until then, we will continue to Zoom across the globe.

\section{ACKNOWLEDGEMENTS}

Thank you to our fabulous global partners that have supported this course through the years: Jan Jukema, Preeti Jagadale, Mayuko Yasuda, Tomoko Ikeuchi, Gail Potter, Gerd Lervik, Irene Liu, San Guan Ong, Montserrat Salvat-Ruiz. Our students have brought enthusiasm, curiosity and a lot of fun to this course. They also provided honest and helpful feedback so that we could improve its delivery each semester. 


\section{REFERENCES}

Elliott, K. (2005). Course design on aging: Incorporating cross-cultural perspectives that challenge assumptions about assessment and service delivery. Gerontology \& Geriatrics Education, 26(1), 23-41.

Fitzgerald, K.G. (2015). Teaching global aging. The Gerontologist, 55(1), 173-176.

Holmes, E.R., \& Holmes, L.D. (1995). Other cultures, elder years (2nd ed.). Thousand Oaks, CA: Sage.

Hou, S. (2018). A Taiwan study abroad program on aging, culture, and healthcare. Educational Gerontology, 44(1), 18-27, DOI: 10.1080/03601277.2017.1386353

Kunkel, S.R., Brown, J.S., \& Whittington, F.J. (2014). Global aging: Comparative perspectives on aging and the life course. New York, NY: Springer Publishing Company.

Li., Y. (Ed.). (2013). Global aging issues and policies: Understanding the importance of comprehending and studying the aging process. Springfield, IL: Charles C. Thomas Publisher.

McDaniel, S.A., \& Zimmer, Z. (Eds.). (2013). Global ageing in the twenty-first century: Challenges, opportunities and Implications. Surrey, UK: Ashgate Publishing.

Mwangi, S.M., Yamashita, T., Ewen, H.H., Manning, L.K., \& Kunkel, S.R. (2012). Globalization of gerontology education: Current practices and perceptions for graduate gerontology education in the United States. Gerontology \& Geriatrics Education, 33(2), 198-217. doi: 10.1080/02701960.2012.661808

Nandan, M. (2005). Cross-cultural perspectives in Thanatology: Through a prism of religious faiths. Gerontology \& Geriatrics Education, 26(1), 43-56.

Shenk, D., \& Groger, L. (2005). Aging Education in a Global Context. Binghamton, NY: The Haworth Press.

Waxman, B. (2008). Teaching cross-cultural aging. Gerontology \& Geriatrics Education, 26(1), 77-95.

WHO and U. S. National Institutes of Health. (2011). Global Health and Ageing. Retrieved from http://www.who.int/ageing/publications/global_health/en/

Yahnke, R.E. (2005). Heroes of their own stories: Expressions of aging in international cinema. Gerontology \& Geritarics Education, 26(1), 57-76. 